\title{
Branding Riau The Homeland Of Melayu Untuk Meningkatkan Daya Tarik Wisata Dan Kunjungan Wisata Di Provinsi Riau
}

\author{
Atika Fajriandhany1, Ilham Gemiharto², Edwin Rizal ${ }^{2}$ \\ ${ }^{1}$ Magister Pariwisata Berkelanjutan, Sekolah Pascasarjana Universitas Padjadjaran, Jl. Dipatiukur No.35 \\ Bandung \\ ${ }^{2}$ Fakultas Ilmu Komunikasi, Universitas Padjadjaran, Jl. Raya Bandung Sumedang KM.21, Sumedang \\ e-mail: fajriandhany@gmail.com, ilham.gemiharto@unpad.ac.id, edwin.rizal@unpad.ac.id
}

\begin{abstract}
ABSTRAK
Branding menjadi salah satu alat atau perantara bagi masyatakat agar dapat kenal dengan sebuah destinasi pariwisata.Penelitian ini menjelaskan bahwa branding merupakan sebuah identitas dalam memperkenalkan potensi dan keunggulan pasriwisata yang ada di daerah tertentu termasuk Provinsi Riau. Maka dari itu pemerintah Provinsi Riau membentuk sebuah branding yang mewakili dan memperkenalkan daya tarik wisara yang ada di Provinsi Riau.Riau The Homeland Of Melayu adalah sebuah tagline branding provinsi riau yang diharapkan dapat memperkenalkan pariwisata Riau yang selama ini menjadi daya tarik Provinsi Riau. Branding ini bukan hanya sekedar logo semata namun branding Riau The Homeland Of Melayu merupakan sebuah keseluruhan ,makna dan nilai yang tertanam di dalamnya. Branding Riau The Homeland Of Melayu juga menjadi brand destinasi yang mecakup unsur wisata dan budaya. Sebuah destinasi pariwisata tidak dipandang sebagai suatu tempat tapi juga dianggap sebagai tempat yang memiliki Cultural dan natural value. Branding inilah yang nantinya di harapkan dapat meningkatkan daya tarik masyarakat terhadap pariwisata Provinsi Riau dan berkunjung ke Provinsi Riau. Branding Riau The Homeland of Melayu ini untuk membangun identitas pariwisata Riau. .Riau The Homeland of Melayu menjadi media untuk menyampaikan gagasan mengenai pariwisata unggulan yang ada di Provinsi Riau. Daya tarik wisata merupakan salah satu dimensi yang sangat penting dalam pembentukan brand pariwisata. Tanpa Adanya daya tarik wisata maka pariwisata mungkin tidak ada yang istinewa dari suatu daerah ini pun akan mengakibatkan tingkat kunjungan wisata akan menurun . Kesalahan dalam mengelola daya tarik wisata akan berdampak pada penurunan citra pariwisata dan juga mengurangi tingkat kunjungan .Penelitian mengunakan metode penelitian studi literatur yang mana mengumpulkan referensi yang relevan dan terkait dalam pembahasan mengenai branding dan brand destinasi. Penelitian ini juga menggunakan metode observasi yang mana peneliti juga mengamati kegiatan promosi seperti apa yang dilakukan oleh pemerintah provinsi Riau dalam hal ini Dinas Pariwisata Provinsi Riau dalam mempromosikan Rau The Homeland Of Melayu .Dalam memepromosikan Branding Riau The Homeland Of Melayu Dinas Pariwisata Provinsi Riau memiliki strategi promosi sendiri antara lain Paid Media, Owned Website dan, Social Media.
\end{abstract}

Kata Kunci: Branding, Riau The Homeland Of Melayu,. Dava Tarik, Kunjungan

\section{Branding Riau The Homeland Of Melayu To Increase Travel Attraction And Tourist Visit In Riau Province}

\begin{abstract}
Branding is one of the tools or intermediaries for people to get to know a tourism destination. This research explains that branding is an identity in introducing the potential and advantages of tourism that exist in certain areas including Riau Province. Therefore the Riau provincial government formed a branding that represented and introduced the attraction of the existing tourism in Riau Province. Riau The Homeland Of Melayu is a tagline of the Riau province that is expected to introduce Riau tourism which has been an attraction for Riau Province. This branding is not just a logo, but Riau's Homeland of Melayu branding is a whole, meaning and value embedded in it. Branding Riau The Homeland Of Melayu is also a destination brand that includes elements of tourism and culture. A tourism destination is not seen as a place but also considered as a place that has Cultural and natural value. This branding is expected to increase the attractiveness of the community towards Riau Province tourism and visiting Riau Province. Riau Branding The Homeland of Malay is to build Riau's tourism identity. Riau The Homeland of Malay became a medium to convey ideas about leading tourism in Riau Province. Tourist attraction is one of the very important dimensions in forming a tourism brand. Without the existence of a tourist attraction, tourism may not be special from this area, which will cause the level of tourist visit will decrease. Mistakes in managing tourism attractiveness will have an impact on the decline in the image of tourism and also reduce the level of visits. Research uses literature study research methods which gather relevant and related references in discussions about branding and destination
\end{abstract}


brands. This study also uses an observation method in which the researcher also observes promotional activities such as what is done by the Riau provincial government in this case the Riau Provincial Tourism Office in promoting Rau The Homeland Of Melayu. In promoting Riau Branding The Homeland Of Melayu The Riau Provincial Tourism Office has a strategy own promotions include Paid Media, Owned Websites and, Social Media.

Keyword: Branding, Riau The Homeland Of Melayu, Tourist Attraction, Tourist Visit

\section{PENDAHULUAN}

Pariwisata saat ini dianggap sebagai suatu hal yang dapat memperkenalkan suatu potensi wisata. Tidak bisa dipungkiri bahwa saat ini pariwisata menjadi suatu penunjang bagi suatu daerah atau Negara. Di Indonesia, pariwisata merupakan suatu hal yang dapat menunjang ekonomi salah satunya meningkatkan devisa negara. Banyak aspek yang mendukung untuk keberlangsungan pariwisata yang maksimal. Mulai dari bagaimana upaya pemerintah dalam meningkatkan potensi wisata, Upaya promosi yang dilakukan dan lain-lain. Dalam meningkatkan pariwisata harus memperhatikan bagaimana objek wisata daerah itu sendiri, sarana dan prasaran yang mendukung dalam industry pariwisata. Usaha untuk mengembangkan suatu daerah wisata harus memperhatikan berbagai macam faktor yang dapat mempengaruhi tuatu daerah tujuan wisata. Faktorfaktor tersebut antara lain objek wisata, daya tarik wisata,sarana dan prasaran, tata letak, dan kondisi dari lingkungan dan masyarakat.

Riau merupakan sebuah provinsi terletak di bagian tengah pulau sumatera. Provinsi Riau terletak di bagian tengah pantai timus pulau sumatera, yaitu sepanjang pesisir selat malaka. Hingga tahun 2004 Provinsi Riau juga meliputu kepulauan Riau. Kepulauan Riau di mekarkan menjadi provinsi tersendiri pada juli 2004 . Ibukota Provinsi Riau adalah Pekanbaru. Saat ini Riau merupakan salah satu provinsi terkaya di Indonesia, dan menjadi sumber daya yang mendominasi di sumber alam, terutama minyak bumi, gas alam, karet. Kelapa sawit, dan perkebunan serat. Provinsi Riau juga memiliki saya tarik wisata yang unggul.
Suatu daerah pasti memiliki identitas sendiri. Identitas ini digunakan untuk dapat membuat orang ingat akan daerah tersebut. Branding yang dimiliki oleh Provinsi Riau adalah Riau The Homeland Of Melayu.

Setiap Organisasi perangkat daerah atau dalam hal ini Dinas Pariwisata Provinsi Riau memuliki Rencana Strategis (Renstra) , Rencana Strategis ini meliputi kegiatan program yang akan dilaksanakan dalam kurung waktu 5 tahun kedepan . Renstra sudah tertuang dalam RPJMD atau Rencana Pembangunan Jangka Menengah Daerah yang di Buat oleh BAPPEDA atau Badan Perencanaan dan Pembangunan Daerah . Riau The Homeland of Melayu merupakan program yang dilaksanakan oleh Dinas Pariwisata Provinsi Riau.

Riau The Homeland of Melayu adalah branding yang diusung pemerintah Provinsi Riau untuk mempromosikan dan memperkenalkan potensi pariwisata unggulan yang selama ini menjadi daya tarik utama pariwisata Provinsi Riau dan dengan harapan mampu meningkatkan tingkat kunjungan wisatawan mancanegara, menggerakkan roda ekonomi, meningkatkan citra dan daya saing daerah dikancah nasional maupun internasional. Provinsi Riau memiliki kekayaan budaya yang beraneka ragam dalam bentuk adat-istiadat, tradisi, kesenian,mapun bahasa.

Masyarakat Riau yang terdiri dari berbagai suku yaitu Melayu dan masyarakat pedalaman seperti suku Sakai, Talang Mamak, Laut, Bonai, Hutan serta suku lainnya yang masing-masing memiliki kebudayaan dan adat istiadat sendiri. Meskipun suku Melayu termasuk yang mayoritas. Sehingga Provinsi 
Riau memiliki objek dan Daya Tarik Wisata (DTW) yang beragam, baik wisata alam, budaya maupun sejarah.

Daya Tarik Pariwisata di Provinsi Riau terdiri dari beberapa macam yaitu, Daya Tarik Wisata Alam, Daya Tarik Wisata Buatan Daya Tarik Wisata Budaya. Berikut penjelasan dari masing masing daya tarik wisata yang ada di Provinsi Riau.

Daya Tarik Wisata Alam Secara geografis, Provinsi Riau tidak memiliki gunung seperti layaknya provinsi tetangganya yakni Sumatera Barat. Hal ini menyebabkan Riau dianggap miskin dengan objek wisata alam yang biasanya banyak terdapat di daerah pegunungan. Namun ternyata jika kita telusuri kabupaten-kabupaten di provinsi ini, kita akan menemukan banyak tempat wisata yang tersembunyi . Banyak objek wisata di Daerah Riau yang tidak terekspos dan tidak diketahui oleh para wisatawan. Disamping promosi yang kurang maksimal, pengelolaan dari tempat-tempat wisata ini pun masih butuh usaha yang lebih serius lagi . Beberapa objek wisata alam yang dapat kita temukan di daerahdaerah kabupaten di Riau adalah Taman Nasional Tesso Nilo, Taman Nasional Bukit Tigapuluh, Hutan Marga Satwa Rimbang Baling, Tahura Sultan Syarif Kasim, Hutan Wisata Buluhcina, Hutan Lindung Bukit Suligi,Bukit Berbunga, Cagar Biosfer Giam Siak Kecil, Wisata Bono Sungai Kampar, Danau Bakuok, Pantai Taman Prepattunggal, Pantai Selat Baru, dan wisata alam lainnya.

Selain wisata alam Provinsi Riau juga memiliki daya tarik wisata buatan yang terdiri dari : Kebun Binatang Kasang Kulim, Taman Agrowisata Bukit Naang, Pusat Pelatihan Gajah, Tugu Equator, Benteng Tujuh Lapis, Penambang Emas logam di antara Pekanbaru dan Teluk Kuantan, Pasar Bawah, Monument Angguk Pompa, Tembatan Tengku Agung Sultanah Latifah, dan lain-lain.
Daya Tarik Wisata Budaya letaknya strategis di Provinsi Riau dijalur lalu lintas perdagangan di Selat Malaka, menyebabkan terjadinya kontak antar suku-suku di sekitar nusantara seperti: India, Arab, dan Eropa. Masuknya agama Hindu, Budha dan Islam menyebabkan terjadinya akulturasi, adaptasi dan asimilasi di bidang kebudayaan. Salah satu warisan Hindu yang nyata adanya adalah Kompleks Candi Muara Takus dikecamatan Tiga Belas Koto Kampar Kabuaten Kampar. Selain itu terdapat pula dipadang Candi di Sintung Kabupaten Indagiri Hulu, Siarangarang dan Sedinginan di Kabupaten Rokan Hilir.dan sebagainya.

Pengaruh agama Islam masuk ke Indonesia pada millenimum pertama dan sesudah terjadi secara damai selama abad ke-14 dan ke-15. Sesudah Agama Islam masuk dan berkembang, Berbagai elemen budaya mengalami penyesuaian agama islam. Dan ini menjadi hal dominan di kebudayaan melayu, seperti tradisi, misalnya, Motto ini distandarisasi “Adat Bersendi Syara', Syara', Bersendi Kitabullah', Sesudah Kerajaan Sriwijaya runtuh, beberapa kerajaan melayu muncul. Di antaranya Bintan, Temasik, Indragiri, Siak, Pelalawan, Gunung Sahilan, Rambah, Rokan IV Koto, Tambusai, Riau Lingga, Kerajaan Kunto Darussalam memainkan peranan penting dalam perkembangan Agama Islam dan Kebudayaan, oleh karena itulah Agama Islam menjadi semakin kuat dan kemudian menyatu dengan nama Komunitas Melayu.

Selain wisata alam, wisata buatan, wisata budaya juga tidak kalah menarik sepertibanyak nya objek wisata budaya yang ada di Provinsi Riau yaitu: Istana Kerajaan Siak,Candi Muara Takus,Makan Koto Tinggi, Istana Kerajaan Rokan, Museum Daerah Sang Nila Utama, Masjid Raya Pekanbaru, Bukit Batu, Mesjid Kerajaan, Rumah Asli Lontiok,Masjid Jami', dan lain-lain. 
Lalu Kegiatan/ Atraksi Periwisata Provinsi Riau memiliki beberapa kegiatan (event) pariwisata yang cukup besar yaitu Pacu Jalur, Bakar Tongkang, Menongkah Kerang, Petang Megang, Provinsi Riau juga masih memiliki event pariwisata lainnya seperti Pekanbaru 10K, Festival Lampu Colok, Festival Budaya Kampar, Festival Danau Raja dan lain-lain.

Berbagai usaha yang terencana sangat diperlukan untuk meningkatkan jumlah kunjungan para wisatawan, baik nusantara maupun mancanegara ke Provinsi Riau. Salah satunya yang bisa ditempuh adalah dengan memperkenalkan dan mengembangkan citra dan potensi tujuan (destination) wisata yang terdapat di Provinsi Riau.

Branding adalah suatu upaya membangun citra positif secara sadar dan terkelola, tanpa usaha ini, identitas dan kepribadian suatu destinasi akan lenyap atau hancur. Dalam konteks suatu kawasan atau deestinasi menjadi promosi dan infrastruktur pembangunan ekonomi, sewajarnya jika digunakan sebagai brand untuk memperjelas identitas dan menonjolkan keunggulan. Melalui brand, aneka pilihan yang simpang siur dan membingungkan pada mata pengguna yang dalam hal ini misalnya stakeholder dalam pariwisata, diperjelas dan dipermudah sehingga kemungkinan besar orang akan membeli produk wisata, karena brand memberikan jaminan kualitas dan memudahkan pilihan. (Bungin 2015:125)

Walau bagaimanapun brand bukan sekedar logo dan slogan, akan tetapi brand lebih dari itu semua, brand memberi nilai kesempurnaan terhadap produk, namun brand produk sering dipahami sebagai konstruksi citra sosial, sehingga produk atau pelayanan tampak lebih baik dari yang sebenarnya:

$$
\text { Kotler dan Pfoertsch }
$$
mengatakan, ... tapi bukan branding bukan hanya logo tetapi lebih dari itu, merupakan totalitas persepsi, pengalaman, perasaan dan citra yang ditangkap oleh semua orang dari suatu produk (Bungin, 2015:125)
Seperti branding yang digunakan untuk pariwisata Indonesia yaitu Wonderful Indonesia yang juga merupakan suatu branding untuk meningkatkan pariwisata di Indonesia agar khalayak tahu identitas Indonesia sebagai negara yang memiliki beragam budaya, adat istiadat yang beragam.

Dalam meningkatkan daya tarik wisata di Provinsi Riau pelru adanya upaya branding yang dilakukan. Dalam hal ini bagaimana upaya branding yang di lakukan dan kegiatan apa yang dilakukan.

Tugas utama city branding ialah mengubah lokasi menjadi destinasi dan juga menjadikan destinasi investasi . setiap kepala daerah sehendaknya sadar tentang menata suatu kota dengan menggunakan branding.

City Branding menjadikan suatu kota sebagai destinasi atau kota tujuan wisata masyarakat lokal maupun mancanegara (Maulida,2016).Maka darii itu konsep city branding menjadikan suatu kota atau daerah memiiki identitas

Potens pariwisata suatu daerah yang
besar apabila dilakukan tanpa oerenanaan
dan pelaksanaan maka tujuan dari kota
tersebut untuk meningkatkan aya tarik
ataupun meningkatkan jumlah kunjungan
tidak akan tercapai dengan maksimal.
Maka dari itu upaya yang dilakukan
adalah melakukan city branding (Hilman
dan megantari,2018).

Maka dari itulah Provinsi Riau membuat perencanaanyaitu membentuk branding yang cocok untuk meningkatkan pariwisata di Provinsi Riau Seperti yang sudah di jelaskan sebelumnya bawah dalam bmebentuk branding Riau The Homeland Of Melayu merupakan baguan dari renstra .

Dalam bidang pariwisata pembentukan brandings sangat mempengaruhi suatu tempat wisata. Jika pembentukan branding tidak tepat ini akan menjadi kesalahan yang sangat besar. (Michandani dan Arida,2019). 
Seperti yang kita ketahui bahwa komunikasi melibatkan tiga unsur yang tidak dapat dipisahkaa yaitu sender, message, receiver. Maka dalam hal ini pembentukan branding dan kegiatan promosi adalah pesan yang akan disampaikan oleh sender ke receiver . Namun, pengemasan pesannya bukan hak yang sederhana karena ini berkaitan dengan identitas daerah tersebut. Pesan tersebut harus memperhatikan dan memperimbangkan berbagai macam aspek yng dapat memrikan dampak yang postitif seperti dapat menyebarkanluaskan informasi kepariwisataan yang secraa potensial tersedia disuatu tempat. . Dapat menjarg wisatawan local dan internasional, dan tetap menjaga kesopanan dan mematuhi aspek di destinasi wisata tersebut. Pesan promosinya harus menarik dan atraktif namun tidak membuat wisatwan tertipu sehingga wisatawan dapat memrikan Positive Word Of Mouth kepada wisawatan lainnya.

Brand destinasi yang bagus haruslah semempunya merubah persepsi dan penilaian orang atau wisatawan dari nefaitif ke positif terhadap wisata yang sesuai dengan kebutuhan mereka selama berkunjung.

Menurut kotler dalam (Rahman,Farida,2017) setiap lokasi juga dapat disebut brand dengan menciptakan dan mengkomunikasikan identitas bagi suatu lokasi yang bersangkutan. Hal tersebut juga menyatakan bahwa destinasi branding dapat memberi oengaruh yang sangat signifikan terhadap word of mouth ke wisaawan yang berkinjung ke provinsi Riau.

\section{METODE PENELITIAN}

Dalam penelitian perlu dilakukannya teknik dalam penyusunan yang sistematis untuk memudahkan langkah-langkah yang akan dilakukan. Maka dari itu dalam penelitian ini melakukan studi literatur pada buku dan jurnal yang terkait dalam tentang branding dan pariwisata dan juga penelitian yang berkaitan dengan branding dan meningkatkan daya tarik wisata dan kunjungan wisata ke provinsi
Riau . Dengan dilakukanny penelitian studi litaratur ini sebagai alat utama terhadap pelaksanaan penelitian. Dalam Penelitian ini juga melakukan teknik observasi sebagai metode penelitian dimana peneliti mengamati dan mengumpulkan data melalui observasi.

Menurut (Kriyantono,2006) Observasi diartikan sebagai kegiatan mengamati secara langsung tanpa mediator sesuatu objek untuk melihat dengan dekat kegiatan yang dilakukan objek tersebut.

Observasi dan wawancara merupakan

metode pengumpulan data yang di gunakan dalam riset kualitatif .

Peneliti melakukan beberapa wawancara di Dinas Pariwisata Provinsi Riau mengenai Branding Riau The Homeland Of Melayu

Menurut (Kriyantono,2014:110) Terdapat beberapa syarat tertentu agar bermanfaat bagi kegiatan pengumpulan data antara lain:

- Observasi digunakan dalam riset dan telah direncanakan secara sistematis

- Observasi harus berkaitan dengan tujuan riset yang telah ditetapkan

- Observasi yang dilakukan harus dicatat secara sistematis dan dihubungkan dengan proposisi umum dan bukan dipaparkan sebagai suatu yang hanya menarik perhatian

- Observasi dapat dicek dan di kontra mengenai fasilitas dan realibilitas

Dalam penelitian ini metode observasi yang dilakukan berupa mengamati kegiatan branding yang dilakukan di media social.

\section{HASIL DAN PEMBAHASAN}

Dalam upaya untuk meningkatkan kujungan wisata dan branding pariwisata ,setiap pemerintah daerah memiliki perangkat daeah masing masing untuk melaksanakan hal teersebut maka dari itu Dinas pariwisata provinsi Riau selaku dinas terkait yang 
menangani pariwisata memilki tugas pokok dan fungsi masing masing.

Dinas Pariwisata Provinsi Riau pada awal berdiri pada tahun 1987 bernama Dinas Pariwisata Daerah Tingkat I Riau dan pada tahun 2003 berubah nama menjadi Dinas Kebudayaan, Kesenian dan Pariwisata Provinsi Riau dan berdasarkan Peraturan Daerah Provinsi Riau Nomor 53 Tahun 2009 berganti nama lagi menjadi Dinas Kebudayaan dan Pariwisata Provinsi Riau. Sesuai dengan perkembangan tentang penataan organisasi Pemerintah Daerah maka disusun Peraturan Daerah Provinsi Riau Nomor 2 Tahun 2014 Tentang Organisasi Dinas Daerah Provinsi Riau (Lembaran Daerah Provinsi Riau Tahun 2014 Nomor 2), dimana berdasarkan Peraturan Daerah tersebut diatur uraian tugas Dinas Pariwisata dan Ekonomi Kreatif Provinsi Riau yang dituangkan melalui Peraturan Gubernur Riau Nomor 25 Tahun 2015 tentang Rincian Tugas, Fungsi dan Tata Kerja Dinas Pariwisata dan Ekonomi Kreatif Provinsi Riau.

Visi Dinas Pariwisata dan Ekonomi Kreatif Provinsi Riau Tahun 2014 - 2019 mengacu pada Visi Provinsi Riau Tahun 2014 - 2019, yaitu :

\section{"TERWUJUDNYA PROVINSI RIAU SEBAGAI} DAERAH TUJUAN WISATA YANG BERDAYA SAING, DIDUKUNG OLEH BUDAYA MELAYU DAN EKONOMI KREATIF UNTUK KESEJAHTERAAN MASYARAKAT"

Pernyataan Visi di atas adalah keadaan yang diharapkan tercapai pada akhir periode perencanaan, sehingga perlu pemahaman terhadap pernyataan visi tersebut sebagai berikut:

a. Daerah Tujuan Wisata, dalam hal ini adalah kawasan geografis yang berada di wilayah Provinsi Riau, yang didalamnya terdapat
Daya Tarik Wisata, Fasilitas Umum, Fasilitas Pariwisata, aksesibilitas, industri, serta masyarakat yang saling terkait dan melengkapi terwujudnya kepariwisataan.

b. Kepariwisataan Yang Berdaya Saing, berarti bahwa Provinsi Riau akan mengembangkan Daerah Tujuan Wisata yang mampu menghadapi persaingan (competion) dengan berbagai Daerah Tujuan Wisata lain, baik di tataran nasional, regional, maupun internasional. Untuk itu diperlukan upayaupaya pengembangan kepariwisataan yang menyeluruh (comperhensive) dan berkelanjutan (sustainable), yang meliputi peningkatan kuantitas dan kualitas Daya Tarik Wisata, Fasilitas Umum, Fasilitas Pariwisata, aksesibilitas, serta pembinaan industri dan masyarakat sebagai pelaku di bidang pariwisata.

c. Budaya Melayu, adalah suatu cara hidup yang berkembang dan dimiliki bersama oleh masyarakat etnis Melayu, terutama yang berada di wilayah Provinsi Riau, yang diwariskan dari generasi ke generasi. Kebudayaan Melayu dengan unsur-unsurnya, yaitu bahasa, sistem pengetahuan, sistem tegnologi dan peralatan, sistem kesenian, sistem mata pencarian hidup, sistem religi, serta sistem kekerabatan dan organisasi kemasyarakatan, merupakan kekayaan dan jati diri anak bangsa, yang akan menjadi faktor pendukung dalam pengembangan pariwisata dan ekonomi kreatif di Provinsi Riau.

d. Ekonomi Kreatif, adalah sebuah konsep di era ekonomi baru yang mengintensifkan informasi dan kreativitas dengan mengandalkan ide dan pengetahuan dari sumber daya manusia sebagai faktor 
produksi yang utama. Karakteristik ekonomi kreatif antara lain berbasis pada ide atau gagasan, pengembangannya tidak terbatas dalam berbagai bidang usaha, serta memerlukan kolaborasi antara berbagai aktor yang berperan dalam industri kreatif, yaitu cendekiawan (kaum intelektual), dunia usaha, dan pemerintah sebagai prasyarat mendasar.

e. Kesejahteraan Masyarakat, mengandung arti bahwa pengembangan pariwisata dan ekonomi kreatif di Provinsi Riau harus berpihak kepada masyarakat. Upaya-upaya pengembangan pariwisata dan ekonomi kreatif akan dilaksanakan selaras dengan pemberdayaan masyarakat sehingga dapat memperbesar peluang usaha, membuka lapangan kerja sekaligus mengurangi kemiskinan sesuai dengan visi Pembangunan Jangka Menengah Daerah Tahun 2014-2019. Pemberdayaan masyarakat akan dilaksanakan melalui penguatan dan pengembangan kapasitas masyarakat sebagai stakeholder pengelola Daerah Tujuan Wisata dan Daya Tarik Wisata.

Pemerintah harus bekerja sama dengan stake holder dan swasta agar pengembangan objek wisata dan daya tarik wisata. Hal ini menjadi kunci agar suksesnya pariwisata di provinsi Riau. Pemerintah Provinsi Riau bekerja sama dengan berbagai pihal dalam pelestarian dan pengembanag pariwisata di Provinsi Riau.

Salah satu alasan mengapa branding Riau The Homeland Of Melayu di gunakan dalam sebagai branding Provinsi Riau adalah karena branding Riau The Homeland Of Melayu menjadi media untuk memberikan ciri khas yang ada di Riau dan mencari branding seperti apa yang cocok untuk Riau agar masyarakat tahu akan ciri khas dari Riau adalah sebagai Tanah melayu.

\section{Makna Riau The Homeland Of Melayu} menggambarkan kesatuan berbagai elemen wisata dan budaya di Provinsi Riau serta memperkenalkan bagaimana luar biasanya alam, budaya dan keunggulan lainnya yang dimiliki sehingga dapat menigkatkan daya tarik wisata bagi pengunjung ke Riau.

Branding Riau The Homeland Of Melayu mmelambangkan perahu lancing kuning yang identik dengan lambang melayu Riau. Dimana Kkemelayuan dalam sejarah di tegakkan engan Ranggi, bersama dengan kehadiran kedayuan, bersambung ke kerajaan-kerajaan besar dan kecil. Kelompokkelompok adat beragam, merwariskan kehidupan budaya yang berkaitan yang bagaiman taman bungabunga kebiasaan dan bahasa yang beraneka.

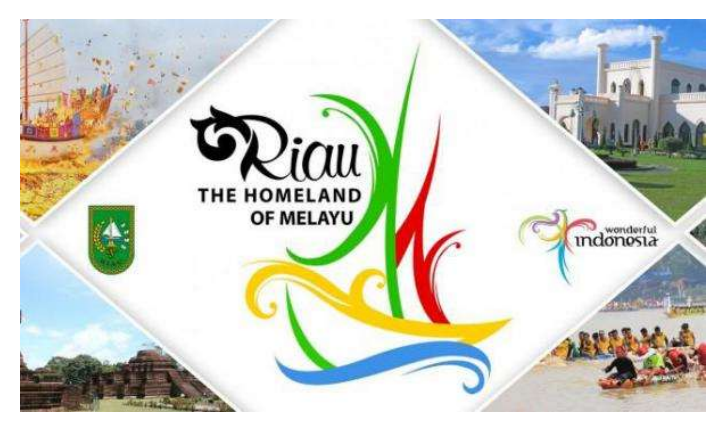

Gambar 1

Branding Riau The Homeland of Melayu Sumber:Hasil Penelitian

Brand destinasi selain memiliki makna yang dibina sebagai produk dari ekonomi modern, Usaha promosi dan kampanye destinasi pariwisata menjadi media dan kegiatan yang penting dalam upaya dari menaikan brand destinasi. Membina brand destinasi sebagai upaya untuk memperkenalkan budaya suatu daerah. Agar wisatawan dapat dengan jelas mengetahuu tentang produk destinasi apa saja yang di tawarkan oleh suatu daerah atau tempat. Tidak lupa juga melakukan perkenalan falsafah budaya, nilai 
suatu budaya dan symbol dan ragam budaya yang menjadi symbol utama (Bungin, 2015:140).

Brand destinasi yang merupakan upaya promosi dan memperkenalkan destinas pariwisata yang ada didaerah itu sendiri. Dari brand destnasi ini mencakup beberapa unnsr budaya daerah yang memiliki brand destinasi sendiri.Brand destinasi adalah kajian tentang brand destinasi dalam kontek brand produk destinasi, dmana brand destinasi adaah media dan pesan itu sendiri di dalam konteks proses komunikasi pemasaran secara umum dan khususnya di dalam konteks komunikasi pariwisata. Selain dikaji, brand sebagai media dan sebagai pesan itu sendiri, dikaji pula bagaimana konstruksi sosial brand destinasi, bagaimana hubungan brand dengan produk destinasi, brand dengan aksesibilitas, dengan pemasaran pariwisata, brand dengan SDM dan kelembagaan pariwisata.

Menurut (Bungin, 2015:78).) terdapat tujuh langkah dalam proses branding destinasi di masyarakat yaitu:

a) Asesmen dan audit yaitu dimana brand destinasi itu berada yang mana brand tersebut memperkenalkan.

b) Analisis dankeuntungan yaitu nilai lebih apa yang diberikan suatu destinasi kepada wisatawan.

c) Posisi brand, yaitu hubungan brand yang digunaan dengan suatu destinasi.

d) Artikulasi yaitu bagaimana brand mengekspresikan visualisasi dan verbalitas dalam iklan dan kampanye brand destinasi.

e) Aktivasi, yaitu bagaimana brand yang mengaktivasi kehidupan yang lebih baik dengan sapaan lain yaitu bagaimana brand membuat hiduplebih baik.

f) Adopsi dan sikap yaitu bagaimana stakeholder suatu destinasi men-support brand destinasi.

g) Aksi dan sesudahnya, yaitu bagaimana brand memberi peluangterhadap pembukaan usaha produktif dalam dunia pariwisata pada sebuah destinasi (dalam

Berdasarkan tujuh langkah proses yang dipaparkan diatas maka ketujuh langkah tersebut harus dilakukan agar proses branding menjadi jelas dan terarah. Hal ini juga mencakup Riau The Homeland of Melayu yang menjadi branding yang dapat dikenal di masyarakat luar dan juga mancanegara melalui branding tersebut maka makna yang terkandung dalam branding Riau The Homeland of Melayu diketahui oleh masyarakat luas.

$$
\text { Selanjutnya menurut (Bungin,2015)) }
$$

mengatakan pula untuk menjadikan branding destinasi yang berhasil seharusnya menjadikan suatu brand itu :
a) trusted
b) can delivera message
c) Unique
d) Media to deliver a stong idea and message.
e) Exciting stakeholders dan partners.
f) Bluffing travelers

Untuk membangun suatu brand destinasi, harus didukung oleh falsafah yang kuat yang bersumber dari budaya Negara atau Daerah tersebut. Brand tersebut digunakan konsisten di semua lapisan masyarakat sehingga menjadi brand yang kuat .Branding Riau The Homeland of Melayu ini untuk membangun identitas pariwisata Riau .Riau The Homeland of Melayu menjadi media untuk menyampaikan gagasan mengenai pariwisata unggulan yang ada di Provinsi Riau.

Menurut Kalandies dalam (Istanto,Somawiharja,Herdinata,Kurniawan,2016) beberapa elemen suatu denstinasi antara lain:

a) Place image.

b) Materiality

c) Intitutions

d) Relations 


\section{e) People and their Pactise}

Elemen ini lah yang di jadikan sebagai acuan dalam membentuk sebuah branding destinasi di Provinsi Riau

Upaya Penerintah dalam meningkatkan kunjungan wisata yang ada di provinsi riau melalui berbagai cara antara lain dengan Branding Riau The Homeland Of Melayu yang mana branding ini di lakukan untuk memperkenalkan daya tarik wisata apa saja yang ada di provinsi Riau, berbagai macam cara yang digunakan oleh Dinas Praiwisata Provisni Riau untuk mempromosikan Riau the Homeland Of Melayu untuk meningkatkan daya tarik wisata yang ada di Provinsi Riau .

Sebuah destinasi pariwisata tidak dipandang sebagai suatu tempat tapi juga dianggap sebagai tempat yang memiliki Cultural dan natural values.Tidak hanya itu destinasi pariwisata adalah tempat dari berbagai atraksi dan related products infrastruktur didalamya dan berbagai fasilitas pariwisata lainnya.

Secata teoritis, brand dapat memberikan value atau nilai terhadap suatu subjek untuk dapat digunakan .dengan memperhatikan teori dengan baik, brand tersebut akan memiliki brand yang bernilai tinggi . jika sebaliknya apabila tidak mempertimbangkan teori, hal tersebut akan membingungkan orang tentang apa yang maksud oleh brand tersebut. Ini dapat menyebabkan kegagalan dalam proses penyampaian Informasi. (Bungin,2017).

Menurut Mcnight dan Stephen dalam Bungin,2017, mengatakan bahwa ada tiga efek komunikasi dalam penyampaian informasi yaitu:

a) Informasi akan langsung diterima oleh penerima pesan tanpa adanya noise atau gangguan.

b) Informasi akan terdistorsi menjadi beberapa bentuk tafsir berdasarkan pada tingkat gangguan yang terjadi ketika informasi itu disebarkan atau pada tingkat kejelasan informasi.

c) Informasi gagal karena ada subjek yang menghalangi, ada noise yang tidak dapat diatasi atau karena informasi yang benar-benar tidak jelas.

Maka dari itu brand akan gagal ketika brand tersebut tidak memiliki muatan dan informasi yang jelas sebagaimana yang telah di sebutkan sebelumnya . brand akan memperlihatkan hal yang ganjal dan akan memperpanjang maasalah apabila brand tidak merepsentasikan suatu produk atau dengan kata lain brand yang gagal. Dalam bidang pariwisata modern hal ini dapat mengembangkan suatu konsep ekonomi yang terbaru agar pariwisata dapat mendorong munculnya usaha-usaha ekonomi, kreatif, ekonomi modern.

Daya tarik wisata merupakan salah satu dimensi yang sangat penting dalam pembentukan brand pariwisata . Kesalahan dalam mengelola daya tarik wisata akan berdampak pada penurunan citra pariwisata. Hal ini juga berdampak pada penurunan tingkat kunjungan.

Citra inilah yang harus dijaga agar perspsi orang dengan destinasi pariwisata tetap bagus . Citra destinasi menurut (Bawanti, 2016) adalah kumpulan dari sejumlah keyakinan, ide dan kesan terhadap destinasi. Citra juga merupakan kesan tentang apa yg dilihat dan juga pemahaman yang diketahui.

Upaya untuk meningkatkan daya tarik ini sekiranya juga dapat mendorong tingkat kunjungan wisata ke privinsi Riau. Bagaiamna upaya yang di lakukan pemerintah dalam hal ini dinas pariwisata untuk meningkatkan kunjungan dengan memaksimalkan daya tarik wisata yang ada di Provinsi Riau.

Dinas Pariwisata Provinsi Riau memiliki strategi dalam memperkenal daya tarik wisata di Provinsi 
Riau tersebut antara lain melakukan promosi bermedia dan promosi langsung.

Startegi promosi bermedia dan promosi langsung dibuat oleh dinas pariwisata provinsi Riau .

\section{A. Promosi Bermedia}

Aktivitas promosi yang dilakukan berupa adanya strategi pemasaran yang dimiliki Dinas Pariwisata, Strategi itu adalah POS (Paid Media, Owned Website,Social Media).

\section{a) Media Cetak}

Dinas Pariwisata selain menggunakan strategi POS juga menggunakan berbagai media cetak antara lain. Banner Riau The Homeland of Melayu, Banner Riau The Homeland of Melayu ini menginformasikan tentang apa itu Riau The Homeland of Melayu dan apa saja ruang lingkup dari Riau The Homeland of Melayu itu sendiri.Selain dari Banner juga terdapat di KOP surat pemerintahan yang melampirkan logo Riau The Homeland of Melayu. Buku statistik pariwisata Provinsi Riau juga termasuk media cetak yang juga digunakan oleh Dinas Pariwisata, buku statitik pariwisata yang dibuat oleh dinas pariwisata ini berisi tentang objek wisata Provinsi Riau dan statistik pariwisata Provinsi Riau.

\section{b) Media Elektronik}

Dinas Pariwisata yang memiliki strategi pemasaran sendiri yaitu POS (Paid Media,Owned Website), media elektronik yang termasuk didalam Strategi POS tersebut adalah Paid media yang dimana paid media itu terdiri dari Discovery Channel, National Geography, Media Group, CNN, Metro TV, ASTRO, CCTV, NET TV, Media Prima.

\section{c) Media Sosial}

Selain media cetak dan media elektronik, media sosial juga digunakan oleh Dinas Pariwisata Provinsi Provinsi Riau dalam mempromosikan Riau
The Homeland of Melayu yang terdiri dari facebook, instagram, twitter dan path.

\section{d) Website}

Website dan Youtube Dinas Pariwisata

Provinsi Riau juga digunakan sebagai media promosi Riau The Homeland of Melayu.

\section{B. Promosi Langsung}

Promosi Langsung merupakan promosi tatap muka yang dilakukan saat kegiatan promosi. Kegiatan promosi langsung yang dilakukan oleh Dinas Pariwisata Provinsi Riau antara lain Pameran di Riau Expo.

Dalam konsep branding menurut (Brakus dkk dalam Judisseno,2019) maka promosi adalah sebiah kegiatan yang berisi paket informasi tentang keberadaan elemen atraksi dan elemen sarana dan parasaranyang tersedia di suatu tempat. Kegiatan promosi bertujuan memengaruhi khalayak agar tertarik untuk mengunjungi destinasi yang di promosikan pada waktu dengan sejumlah biaya tertentu. Konsep ini didasari oleh kemampuan dalam membangun persepsi orang tentang suatu brand destinasi. Orang-orang diajak untuk membayangkan suatu destinasi sebelum mereka memutuskan mengunjungi suatu tempat wisata. Namun tingkat kepuasan tergantung terpenui atau tidak kebutuhan informasi mereka.

Perkembangan teknologi yang saat ini membawa pengaruh terhadap proses promosi pariwisata dan semakin berkembangnya teknologi masa kini maka tidak bisa kita punkiri bahwa pesaingan akan semakin ketat. Di era digital saat ini informasi mengenai pariwisata dapat ditemukan dengan mudah. Hal ini dapat merubah persepsi dan dapat mengubah perilaku orang. 


\section{KESIMPULAN}

Riau The Homeland of Melayu merupakan sebuah tagline branding yang disusung oleh penerintah Provinsi Riau untuk memperkenalkan pariwaiata di privinsi riau dan meningkatkan kunjungan di Provinsi Riau, Branding ini di harapkan juga dapat meningkatkan citra dan daya saing provinsi Riau di secara nasional dan internasional. Banyak daya Tarik wisata di Provinsi Riau yang selama ini menjadi unggulan di Provinsi Riau. Tentunya hal ini dapat diharapkan dapat meningkatkan jumlah kunjungan wisatawan ke Provinsi Riau. Hal ini tentunya dapat menggerakkan roda ekonomi Provinsi Riau agar masyarakat mendapatkan keuntungan dalam bidang ekonomi . berbagai macam upaya yang dilakukan agar branding Riau The Homeland Of Melayu dapat meningkatkan daya tarik dan meningkatkan kunjungan wisata ke Provinsi Riau.

Suatu daeah harus memiliki identitas sendiri. Identitas ini digunakan untuk dapat membuat orang ingat akan daerah tersebut.

Riau The Homeland Of Melayu merupakan program yang dilaksanakan oleh Dinas Pariwisata Provinsi Riau yang mana tercantum dalam Renstra yang akan dilaksanakan dalam kurung waktu 5 tahun.. Renstra tertuang dalam RPJMD atau Rencana Pembangunan Jangka Menengah Daerah yang di Buat oleh BAPPEDA

Salah satu alasan mengapa branding Riau The Homeland Of Melayu di gunakan dalam sebagai branding Provinsi Riau adalah karena branding Riau The Homeland Of Melayu menjadi media untuk memberikan ciri khas dan mencari brand yang cocok untuk Riau

Dinas Pariwisata Provinsi Riau selaku organisasi perangkat daerah yang menjalankan program terciptanya pariwisata yang maju memiliki strategi dalam meningkatkan daya tarik wisata melalui Branding Riau The Homeland Of Melayu. Adapun upaya yang dilakukan antara lain menggunakan Promosi berbedia dan promosi Langsung. Promosi bermedia yang dilakukan menggunakan berbagai macam media yaitu media cetak,media elekteronik, media social, website. Dan promosi langsung menggunakan promosi tatap muka seperti acara pameran Riau Expo. Melalui hal inilah sekiranya dapat memperkenalkan pariwisata Provinsi Riau melalui Branding Riau The Homeland Of Melayu untuk meningkatkan kunjungan ke Provinsi Riau

\section{DAFTAR PUSTAKA}

\section{Buku}

Bungin, Burhan.2015. Komunikasi Pariwisata (Pemasaran dan Brand Destinasi). Jakarta: Kencana Prenada Media Group.

Judisseno, Rimsky J. 2019. Branding Destinasi dan Prmosi Pariwisata . Jkarta: PT.Gramedia Pustaka Utama

Kiyantono, Rachmat. 2014. Teknik Praktisi Riset Komunikasi. Jakarta: Kencana Prenada Media Group.

Utama, I Gusti Bagus Rai, (2015) Pengantar Idustri Pariwisata, Yogyakarta: CV.Budi Utama.

Dinas Pariwisata,2017.Rancangan Peraturan Gubernur :Pekanbaru

\section{Jurnal}

Ahman, Ridho . Farida Naili. (2017). Pengaruh Destination Branding dan Produk Wisata Terhadap Niat Berkunjung Kembali Melalui Word Of Mouth (Studi Kasus Pada Objek Wisata Alam Ga Kreo Semarang).

Bawanti, Ari. (2016). Analisis City Branding Dalam pengembangan Destinasi Pariwisata Kabupaten Jayapura.(Vol.14, No.1) 
Bungin, Burhan. (2017). Kontruksi Realitas Brand

Destinasi Wajah Manis Destinasi

Pariwisata.Sidoarjo.

Maulida, Desi.(2016). Tourism Destination Branding

:Analisi Strategi Branding Wisata Hala "The

Light Of Aceh”.

Emrizal. (2016). Destination Branding Dalam Strategi Pemasaran Destinasi. (Vol.8, No.2).

Hilman, Yusuf Adam dan Megantari, Krisna (2018).

Model City Branding Sebagai Strategi penguatan Pariwisata Lokal Provinsi Jawa Timur.(Vol.2 No.2).

Istanto, Freddy Handoko. Somawijaya, Yohanes, Herdinata, Christian.. Kurniawa, Mixhael N. (2016). Pengembangan Potensi Wisata berbass Brand Destination. Jakarta

Michandani, Eka Shinta. Arida. Inyoman Sukma. (2019). Perancangan Destination Branding Desa Wisata Kerta Kabupaten Gianyar.

Munir, Berlianti, (2017). Branding Riau The Homeland Of Melayu dalam mempromosikan Pariwisata Provinsi Riau (Vol.4 No.1).

Yudistiadhi, Ghifari, Dewi Lupita Sari, Shinta. (2017). Strategi Branding Pariwisata Indonesia Untuk Pemasaran Mancanegara. (Vol.2, No.2).

\section{Website}

https://pariwisata.riau.go.id/ 